\title{
The Professional Socialization of Early Career Medical Laboratory Scientists
}

\section{JANNA SCHILL}

\begin{abstract}
The medical laboratory science profession has faced more than twenty-years of a workforce shortage. One component that plays a role in the workforce shortage is the attrition of early career medical laboratory scientists shortly after graduation from an accredited medical laboratory science educational program. This study seeks to identify factors that contribute to the professional socialization of early career clinical laboratory scientists. In this study early career medical laboratory scientists' express high levels of professional behaviors and attitudes coupled with a strong professional identity necessary to remain in the medical laboratory science profession. In addition, this study identified the presence of a theorypractice transition gap that may contribute to retention and attrition of new professional's as they transition from the classroom into the medical laboratory workforce.
\end{abstract}

ABBREVIATIONS: MLS - Medical Laboratory Science, RG - Recent Graduate, NAACLS - National Accrediting Agency for Clinical Laboratory Science, ASCLS - American Society for Clinical Laboratory Science

INDEX TERMS: Professional socialization, early career; medical laboratory scientist; retention, attrition

Clin Lab Sci 2017;30(1):15

Janna M. Schill, PhD, MLS(ASCP) $)^{C M}$ University of North Dakota Department of Medical Laboratory Science 1301 N Columbia Road Stop 9037 Grand Forks, ND

Address for Correspondence: Janna M. Schill, PhD, $M L S(A S C P)^{C M}$ University of North Dakota Department of Medical Laboratory Science $1301 \mathrm{~N}$ Columbia Road Stop 9037 Grand Forks, ND 58202, 701-777-6302, janna.schill@med.und.edu

\section{INTRODUCTION}

The medical laboratory science (MLS) profession has faced a continual workforce shortage for more than twenty years. ${ }^{1,2,3,4}$ Causes of the long-standing workforce shortage include insufficient numbers of new graduates entering the workforce, poor retention of new professionals, and an increase in the number of professionals who are eligible for retirement. In the shortterm, the number of experienced professionals eligible for retirement is greater than the number of new graduates entering the workforce. ${ }^{5,6}$

According to the United States Bureau of Labor Statistics, medical laboratory science is expected to grow faster than average when compared to other occupations. ${ }^{6}$ In order to continue to maintain adequate staffing that will ensure quality patient care, medical laboratories need to strive to enhance the retention of early-career medical laboratory scientists.

Previous studies by both Firestone and Finnegan ${ }^{7}$ and Beck and Doig ${ }^{8,9}$ have explored retention of early-career medical laboratory scientists. Firestone and Finnegan ${ }^{7}$ found that "only $43 \%$ of new graduates in medical laboratory science saw themselves remaining in the profession five years later." Beck and Doig' found that the more prepared a new graduate felt to practice in MLS, the more likely the individual was remain in the field. Many early career medical laboratory scientist's, who leave the profession of medical laboratory science, seek advanced training in a related health care profession and viewed the profession as a "stepping-stone" to future career plans. ${ }^{9}$

Other allied health professions such as nursing, ${ }^{10}$ pharmacy ${ }^{11}$ and athletic training ${ }^{12}$ have sought to identify factors that influence a new professional's likelihood of remaining in a chosen profession and all have concluded that the professional socialization process directly influences the retention of its members. Research that focuses specifically on the professional socialization of 


\section{CLINICAL PRACTICE}

medical laboratory scientists is lacking but has been previously identified as a needed area of study by McClure. ${ }^{13}$ McClure ${ }^{13}$ states "the need to discover and understand the attitudes and perceptions towards a career in [medical] laboratory sciences...is a key element in understanding what is necessary to maintain the vitality of the $[\mathrm{MLS}]$...profession."

Bragg $^{14}$ defines professional socialization as a process by which an individual develops the requisite skills, knowledge, attitudes, and beliefs necessary for successful transition to professional status". Successful professional socialization must include three distinct characteristics: it is a continuous process that evolves through different stages over time, it includes formal and informal learning, and it involves social interaction.

As a member of a profession, an individual adopts certain behaviors and attitudes through informal and formal interactions with other professionals in a learning or work environment. Bragg ${ }^{14}$ states, "the end product of the socialization process is the incorporation of group values and norms into the individual's self-image."

\section{Attitudes and behaviors}

Attitudes and behaviors are one of several factors that influence an individual's professional socialization. The more positive an individual's professional attitudes and behaviors, the more likely an individual will remain in the profession. For early career medical laboratory scientists, the initial experience that influence one's professional behaviors and attitudes occurs prior to workforce entry during a clinical internship. After obtaining initial employment, professional behaviors and attitudes of early career medical laboratory scientist change as a new professional transitions from student to scientist.

McClure $^{13}$ examined the perspectives of medical laboratory scientists with varying amounts of work experience from early to late career. A major finding in this study was the higher amount of positive attitudes in laboratory professionals with less than two years of experience than those with 4 to 10 years of experience. Short-term responses, such as increase in pay, may only temporarily change attitudes and behaviors. Doig \& Beck $^{8}$ found that a higher level of autonomy and independence were two key factors found to enhance job satisfaction.

\section{Professional identity}

An individual's professional attitudes and behaviors influence professional identity. A person with a strong professional identity will express more positive professional attitudes and behaviors. Formation of a strong professional identity is one of three factors that influences the professional socialization process. Mooney ${ }^{15}$ and Pitney ${ }^{11}$ found that early career nurses and athletic trainers, respectively, who formed a strong professional identity were more likely to remain in the profession compared to their counterparts who had a lower professional identity.

Butina and Schell ${ }^{16}$ qualitatively studied the professional identity of experienced medical laboratory scientists. Study findings identified three emergent viewpoints, "misunderstanding of the profession by other health care professions, general unawareness by the public, [but] vital to patient care, with a general finding that medical laboratory scientists have a poor professional identity. Nursing and pharmacy have both extensively studied the professional identity of early career professionals and found that interactions with more experienced professionals prior to and during initial employment directly influences the formation of one's professional identity.

As a new medical laboratory scientist gains initial employment in a medical laboratory, gaps are identified in an existing professional identity. The gap between the "ideal" and the "reality" of a profession has been defined as a theory-practice gap. ${ }^{17}$ The period of time that an individual is navigating the theory-practice gap has been termed in the literature by others as "transition shock", ${ }^{18}$ "reality shock", ${ }^{19}$ or an "abrupt awakening". ${ }^{20}$ The ability of a new professional to navigate through the theorypractice gap influences the decision to remain or leave within a chosen profession.

This study sought to identify the factors that influence along with the professional socialization of early career medical laboratory scientists. Specifically, this study sought to address several questions:

1. What are the professional behaviors and attitudes are expressed by early career medical laboratory scientists?

2. What are the factors that influence the professional identity among early career medical laboratory 


\section{CLINICAL PRACTICE}

scientists with less than one year of work experience compared to individuals with one to three year's work experience?

3. What is the professional socialization process of early career medical laboratory scientists?

\section{Materials and Methods}

This study utilized a concurrent mixed-method research design. The purpose of a concurrent mixed methods research design is "when the researcher wants to triangulate the methods by directly comparing and contrasting qualitative statistical results with qualitative findings for corroboration and validation purposes." 21

\section{Quantitative data}

The attitudes and behaviors of early career medical laboratory scientists were quantitatively measured using Hall's Professionalism Scale ${ }^{22}$ as adapted by Snizek. ${ }^{23}$ Hall's Professionalism Scale focuses on the attitudes and behaviors in regards to five sub-categories of a profession: professional organizations, service to society, selfregulation, calling to the field, and autonomy. ${ }^{22}$ The survey instrument has twenty-five total questions, with each professional tenet consisting of five questions. Hall's Professionalism Scale ${ }^{22}$ has measured professional attitudes and behaviors in other professions including nursing, medicine, engineering, education, occupational therapy ${ }^{25}$, and accounting. ${ }^{22,23,24,25} \mathrm{~A}$ review of medical laboratory science literature, since 1980, did not identify any studies utilizing this survey instrument.

\section{Qualitative data}

At time of survey submission, study participants volunteered to participate in an online focus group session. Participants volunteered to participate in the online interview. In order to eliminate bias, participants joined the focus group interviews using a private link and logged into the site anonymously. An online focus group format allowed for participation regardless of geographic location. Data collection and transcription of focus group interviews utilized Adobe Connect ${ }^{\mathrm{TM}}$.

\section{Mixed method analysis}

In order to connect qualitative and quantitative information together, this study utilized mixed method data triangulation (Table 1).

\section{Participants}

Participant recruitment was from a single NAACLS accredited medical laboratory science program. Participants were place into one of two groups: recent graduate (RG) or novice medical laboratory scientist (NOVICE). All RG participants were graduates from an accredited laboratory science program within the three months prior to study participation. NOVICE participants were graduates of a NAACLS accredited program but had one to three years of work experience after graduation.

A total of one hundred and forty-one individuals were identified as possible participants, with one-hundred and twelve, 69 RG and 43 NOVICE, contacted using email. Twenty-four RG surveys $(34.8 \%$ response rate) and twenty-one novice surveys (48.8\%) completed the online survey.

Study participation was voluntary with anonymous responses collected. Prior to data collection, the study obtained Institutional Review Board approval at the sponsoring institution. Data analysis utilized IBM SPSS Statistics Version 19.

Since the participants in this study are from a single medical laboratory science program, generalizability of this study may be limited. In addition, the online format utilized by the mixed-methods study may have discouraged participation from some study participants.

\begin{tabular}{llll}
\hline Table 1. Mixed Method Research Analysis Process & & \\
\hline Research Topic & $\begin{array}{l}\text { Process of Professional } \\
\text { Socialization of Early Career } \\
\text { Clinical Laboratory Scientist }\end{array}$ & $\begin{array}{l}\text { Sense of Belong to CLS } \\
\text { profession. }\end{array}$ & Attitudes \& Behaviors \\
Data Collection & $\begin{array}{l}\text { Merging of Quantitative Survey } \\
\text { with Qualitative Focus Group }\end{array}$ & $\begin{array}{l}\text { Focus Group Interviews; } \\
\text { Transcripts of Interviews }\end{array}$ & $\begin{array}{l}\text { Quantitative Data } \\
\text { Halls Professionalism Scale }\end{array}$ \\
& $\begin{array}{l}\text { Data } \\
\text { Mixed Method Triangulation }\end{array}$ & $\begin{array}{l}\text { Coding, Category, and Theme } \\
\text { Identification }\end{array}$ & $\begin{array}{l}\text { Descriptive and Inferential } \\
\text { Statistics }\end{array}$ \\
\hline
\end{tabular}




\section{CLINICAL PRACTICE}

\begin{tabular}{lcccccc}
\hline \multicolumn{7}{c}{ Table 2. Professional behaviors and attitudes of early career clinical laboratory scientists. } \\
\hline & \multicolumn{2}{c}{ RG } & \multicolumn{2}{c}{ NOVICE } & \multicolumn{2}{c}{ RG compared to NOVICE } \\
\hline Halls Professionalism Scale Category & Mean & SD & Mean & SD & t (df $=43)$ & Significance \\
Professional Organizations & 3.48 & .888 & 3.35 & .899 & .502 & $>0.050$ \\
Duty to the Public & 3.86 & .885 & 3.85 & .748 & 0.30 & $>0.050$ \\
Calling to the field & 4.15 & .567 & 3.81 & .974 & 1.45 & $>0.050$ \\
Self-regulation & 4.64 & .514 & 4.17 & .912 & 2.174 & $<0.050$ \\
Autonomy & 3.47 & .958 & 3.57 & .842 & -.333 & $>0.050$ \\
\hline
\end{tabular}

\section{Behaviors and attitudes}

RG participants had higher behaviors and attitudes in four of the five tenets of a profession: professional organizations, duty to the public, calling to the field, and self-regulation, of a profession than the NOVICE group. NOVICE participants expressed a higher level of autonomy than the less experienced RG group. When comparing the differences in means between the RG and NOVICE groups, the only category with a significant difference in means was the self-regulation category (Table 2).

\section{Sense of belonging to the profession of medical laboratory science}

An individual's personal experiences shape the amount of expressed professional identity. In order to identify and generalize the professional identity of early career medical laboratory scientists, this study gathered information utilizing focus group interviews. Eleven individuals (8 RG; 3 NOVICE) participated in the interview portion of this study.

RG participants identified themselves as members of the medical laboratory science profession, were excited to be a member of the medical laboratory science profession, and a planned to remain in the MLS profession for greater than five years. A primary experience that influenced RG participant's sense of belonging to the profession of medical laboratory science was a clinical internship. Interviewees readily identified a point in time in which they identified a shift from "student" to "a member" of the MLS profession. One participant described the transformation from student to medical laboratory scientist as:

Yes, probably after about $2 / 3$ of the way in (my clinical internship). By then I knew how to do just about everything in the lab so I was doing a lot of the lab work. However, they didn't treat me as if it was my responsibility to do the work. I could have been less involved if I wanted to.
In addition to identifying as a member in the MLS profession, recent graduates expressed a positive viewpoint about the MLS profession and confident in the skills acquired as a part of their formal education. One focus group respondent stated:

I feel very confident about being a medical laboratory scientist. Maybe it sounds conceited, but I really feel like I am going to be a great medical laboratory scientist. The education and clinical internships prepared me well.

An additional gap in time since completion of one's formal education resulted in a change in the sense of belonging for NOVICE focus group participants. Themes that emerged from NOVICE participants included: an overall frustration with colleagues who express negative viewpoint of the MLS profession, a desire to find one's "niche", and a desire to be assigned additional job responsibilities or duties. NOVICE participants identified the presence of a poor workplace culture as a key reason to leave the profession.

Interview topics related to current and future career goals and interactions with other medical laboratory scientists identified differing professional identities among RG compared to NOVICE participants. Table 3 provides a comparison and examples of the differing professional identities expressed by early career medical laboratory scientists.

\section{Discussion \& Conclusion}

Early career medical laboratory scientists expressed differing stages of professional socialization into the MLS profession. Less experienced medical laboratory scientist's (RG) self-identified themselves as members of the MLS profession but had not transitioned to full enculturation. On the contrary, NOVICE professionals had navigated through the theory-practice gap but encounter a transitional stage of professional socialization. During the transitional stage an individual's experiences 


\section{CLINICAL PRACTICE}

Table 3. Variations in sense of belonging between early career medical laboratory scientists.

\begin{tabular}{|c|c|c|}
\hline Topics & Recent graduate (RG) & Novice MLS (NOVICE) \\
\hline $\begin{array}{l}\text { Current career } \\
\text { goals }\end{array}$ & $\begin{array}{l}\text { Interview Question: } \\
\text { Where have you been hired to work? } \\
\text { - A smaller facility as a generalist, where I will } \\
\text { be doing all departments in the lab every day } \\
\text { (rotating phlebotomy) } \\
\text { - As things go right now; a hospital with about } \\
25-30 \text { beds } \\
\text { Want to stay in current position for a period less } \\
\text { than five years. } \\
\text { Interview Question: How long do you plan on } \\
\text { staying at your place of hire? } \\
\text { - The plan is for about } 4 \text { years } \\
\text { - At least } 2 \text { years I would say } \\
\text { - } \quad 2-4 \text { years } \\
\text { Expect career advancement opportunities. } \\
\text { I think there are rumors of a promotion if } \\
\text { things go well. (we'll see, lots of promises } \\
\text { were made to get me to stay, so if any of them } \\
\text { come true I'll be happy. }\end{array}$ & $\begin{array}{l}\text { Have left first position and shifted to a different hospital. } \\
\text { - After I graduated and passed the boards I was } \\
\text { employed there as a night shift med tech for a little } \\
\text { over } 2 \text { years. I currently am employed on a rotating } \\
\text { scheduling in a large health care facility in a major } \\
\text { metropolitan area. } \\
\text { - Stayed in my first position for a little more than eight } \\
\text { months, moved to a different state and have been } \\
\text { employed in a facility for a little over a year. At the } \\
\text { end of the month I will be taking a new position in a } \\
\text { different state. } \\
\text { Have sought out extra responsibility. } \\
\text { - } \quad \text { I am the head of the Chemistry Department. } \\
\text { Been offered a position of laboratory manager in a } \\
\text { different state. Will be relocating to become a } \\
\text { laboratory manger with less than three years of full- } \\
\text { time experience. } \\
\text { Looking for a niche. } \\
\text { - I think I may try working in a microbiology } \\
\text { laboratory lab first and see how I like that. } \\
\text { I like working in the lab. I don't have much interest in } \\
\text { transferring to an area of health care where I would be } \\
\text { dealing directly with patients routinely. I would like to } \\
\text { make this profession work for me }\end{array}$ \\
\hline $\begin{array}{l}\text { Future career } \\
\text { goals. }\end{array}$ & $\begin{array}{l}\text { Plan to seek an advanced education in clinical } \\
\text { laboratory science. } \\
\text { - } \quad \text { I do want to get my masters } \\
\text { - } \quad \text { Start my masters } \\
\text { - } \quad \text { I want to go on and get more education in lab } \\
\text { management-related issues. }\end{array}$ & $\begin{array}{l}\text { Sometimes feel like knowledge is underutilized. } \\
\text { - Sometimes I feel more like a troubleshooting expert } \\
\text { for qc or instrument breakdowns than a medical } \\
\text { professional. } \\
\text { May leave field for other health care positions } \\
\text { - Lately I've been debating looking for a job with a large } \\
\text { corporation like Siemens or Beckman Coulter. } \\
\text { Eventually I'd like to go back and get my RN }\end{array}$ \\
\hline $\begin{array}{l}\text { Working } \\
\text { alongside more } \\
\text { experience } \\
\text { laboratory } \\
\text { professionals. }\end{array}$ & $\begin{array}{l}\text { More experienced techs are unfriendly to early } \\
\text { career colleagues. } \\
\text { - I think there were some areas that the techs } \\
\text { did not want me to be in there "territory" so } \\
\text { to speak. } \\
\text { - I make others feel uncomfortable and they } \\
\text { don't want to work by me. }\end{array}$ & $\begin{array}{l}\text { Laboratory climate needs to change to retain workers. } \\
\text { - There is a lot of negativity out there about this } \\
\text { profession, mostly from the people who have been } \\
\text { doing it the longest. } \\
\text { At times there is too much drama in the laboratory } \\
\text { between coworkers. It's hard working with women } \\
\text { who have been there for } 20-30 \text { years. }\end{array}$ \\
\hline
\end{tabular}

influences the decision to remain or leave the medical laboratory science profession.

An initial description of the professional socialization model of medical laboratory science model is similar to the Rosch and Reich ${ }^{27}$ model. While other professions such as nursing ${ }^{28}$ and social work ${ }^{29}$ have indicated that their professional socialization process begins to prior to individuals entering into a formal education setting, this study could not support this finding with MLS because many of the study participants were not aware of medical laboratory science prior to enrollment in a higher education institution. An expanded research study that collects data from more than one NAACLS accredited program and nationwide recent medical laboratory science graduates will allow further explore the beginning of professional socialization for medical laboratory scientists.

Early career medical laboratory scientist's express high levels of professional behaviors and self-identify themselves as members of the medical laboratory science profession. Positive expression of professional attitudes and behaviors are a vital component to retention of new medical laboratory science professionals. In addition, early career medical laboratory scientists demonstrated 


\section{CLINICAL PRACTICE}

positive professional commitment behaviors such as membership and participation in professional societies.

Membership in a professional organization is one aspect that influences workforce retention. Professional organizations such as the American Society for Clinical Laboratory Science has increased its support of early career professionals by offering a discounted membership rate for new medical laboratory science graduates. In addition, ASCLS has committees, leadership positions and professional networks that are solely focused on supporting its early career MLS professionals.

An early career medical laboratory scientist who is able to adapt through the medical laboratory science theorypractice gap by adapting individual attitudes and behaviors and adjusting to a more realistic workplace culture has a greater chance of continuing to be a member of the MLS profession. Once an individual chooses to remain in MLS they transition into the final stage of professional socialization, commitment. ${ }^{27}$

One-way MLS can enhance the retention of early career medical laboratory scientists is for employers to provide a mentorship system that supports a new graduate as they transition through the theory-practice gap. A mentor can provide support to the new graduate as they transition from the structured setting of the classroom into the more flexible working environment. Mentorship would not focus on completion of specific job duties or tasks rather a more experienced medical laboratory scientist would provide guidance in regards to workplace culture such as managing personal time when working an off shift, work-life balance in the continual, high stress laboratory setting, and interacting with colleagues within and outside the laboratory. In a related healthcare profession, nursing, the implementation of a year-long mentorship program for new graduates improved retention rates and morale of new hires. ${ }^{15}$

A second way the MLS profession can improve retention is to recognize the presence of different stages of professional socialization in early career medical laboratory scientists. A workplace that supports and encourages early career medical laboratory scientist's while progressing into the enculturation stage of professional socialization will have increased retention. Related allied health professionals have studied the professional socialization process as a way to identify factors that increase retention of early career professionals and have indicated positive findings. ${ }^{11,12,15}$

When comparing the two groups of participants, RG expressed a higher sense of belonging to the MLS profession than the NOVICE group. A higher sense of belonging expressed by less experienced individuals may be a result of unrealistic or idealistic views of their professional lives and thus the presence of a theorypractice gap. Arthur ${ }^{30}$ found that new nurses often enter the nursing profession with unrealistic career expectations. As the early career clinical laboratory scientists acquire more information about the realities of their day-to-day tasks and career advancement opportunities, and become matriculated into the workplace culture of the laboratory, the sense of the belonging to the profession decreases.

NOVICE medical laboratory scientists still expressed a desire to remain as members of the MLS profession but are influenced by dynamics of a high-stress work environment and unanticipated career plans of a slower career advancement into a leadership role. A previous study by McClure ${ }^{31}$ found that the lack of professional advancement opportunities influenced the retention of clinical laboratory scientists with 5 to 10 years of experience. This study finding may indicate that the MLS profession needs to examine the scope of practice of a board-certified medical laboratory scientists and continue to adjust the levels of practice of the profession as a way to increase the perceived advancement opportunities available to early-career medical laboratory scientists as a way to increase retention.

An unexpected finding in this study was the awareness of the early career clinical laboratory scientists of the challenges that are facing the MLS profession. During the course of this study, the negative aspects of the workplace and laboratory profession were topics participants repeatedly stated as part of the focus group interviews in both RG and NOVICE groups. While one might expect the NOVICE group to be aware of this, one would not expect the newly graduated to have picked up on this.

A study by Gray and Smith ${ }^{32}$ found that the poor attitudes of experienced nurses have been found to influence the professional socialization of early career nurses. This seems to hold true for these early career MLS 
professionals, as well. The primary frustration about the MLS profession expressed by study participants was the negative image of the profession that is portrayed by a small group of its members. The early career clinical laboratory scientists readily stated that the negative image of the laboratory starts in the laboratory. These early career clinical laboratory scientists whole-heartedly agreed that these individuals need to change their negative attitudes into positive attitudes. They believe that the positive attitudes will drive change and increase respect for the laboratory profession, both within itself and with other allied health care professionals and the public. Future research should be conducted to explore the factors that contribute to the negative aspects of the medical laboratory science workplace.

In order to provide an expanded analysis of the professional socialization in medical laboratory science, nationwide studies need to be conducted that identify professional attributes and sense of belonging of clinical laboratory scientists with different levels of work experience. Future research within the area of professional socialization should utilize mixed method research methodology.

This initial pilot study assisted in identifying factors that may contribute to the retention of early career medical laboratory scientists but expanded studies to a nationwide audience are essential to continue the exploration in ways to identify the factors that influence the retention and attrition of new medical laboratory science professionals in the United States.

\section{REFERENCES}

1. Hansen K, Lavanty D. Laboratory personnel shortages. Clin Lab Sci 2001,14(3),130.

2. Kaplan R, Burgess T. The impending crisis. J Microbiol Biol Educ 2010;11(2), 140-3.

3. Karni K. Employment patterns and turnover among laboratory personnel: a twenty-year study. J Allied Health 1993;22(2),15774.

4. Thompson $\mathrm{N}$, et al. The current state of medical laboratory staffing with certified versus noncertified personnel. Lab Med 2009;40(4),197-202.

5. Garcia E, et al. American Society for Clinical Pathology's 2011 Vacancy Survey of U.S. Clinical Laboratories. Lab Med 2011;42(4):199-205

6. Occupational Outlook Handbook, Medical and Clinical Laboratory Technologists and Technicians, Bureau of Labor Statistics, U.S. Department of Labor. Available from http://www.bls.gov/ooh/healthcare/medical-and-clinical-labora tory-technologists-and-technicians.htm. Accessed November 21,2016 .
7. Firestone DT, Finnegan K. Career choices and professional attitudes of graduating clinical laboratory science students: A nationwide survey. Clin Lab Sci 1997;10(1):15-8.

8. Beck S, Doig K. Laboratory Managers' views on attrition and retention of laboratory personnel. Clin Lab Sci. 2005;18(4):23847

9. Beck S, Doig K. Are new CLS practitioners prepared to stay? Clin Lab Sci 2007;20(3):161-71.

10. Deppoliti D. Exploring how new registered nurses construct professional identity in hospital settings. J Contin Educ Nurs. 2008;39(6):255-62. Doi:10.3928/00220124-20080601-03.

11. Pitney W, Ilsey P, Ritala J. The professional socialization of certified athletic trainers in the National Collegiate Athletic Association Division I context. J Athl Train. 2002;37(1):63-70.

12. Hatoum $\mathrm{H}$, Smith $\mathrm{M}$. Identifying patterns of professional socialization for pharmacists during pharmacy schooling and after one year in practice. Am J Pharm Educ. 1987;51:7-17.

13. McClure K. Student perceptions of the clinical laboratory science profession. Clin Lab Sci. 2009;22(1):16-21.

14. Bragg A. The socialization process in higher education (ERIC/Higher Education Research Report No. 7). 1976. Washington, DC: American Association for Higher Education. (ERIC Document Reproduction Service No. 132909)

15. Mooney M. Professional socialization: the key to survival as a newly qualified nurse. Int J Nurs Pract. 2007;13(2):75-80.

16. Butina M, Schell J. Does Professional Identity Affect the Shortage of Hospital Laboratory Personnel? Clin Leadersh Manag Rev. 2011;25(2):10-5

17. Maben, J., Latter, S., \& Clark, J. M. The theory-practice gap: impact of professional-bureaucratic work conflict on newlyqualified nurses. Issues and Innovations in Nursing Education. 2006;55(4):465-77.

18. Harwood, M. Transition-shock - Hitting the ground running. Nutringa. 2011.

19. Kramer, M. Reality shock: why nurses leave nursing. 1974. St. Louis, Missouri.

20. Thrysoe, L., Hounsgaard, L., Dohn, NB, \& Wagner, L. (2011). Expectations of becoming a nurse and experiences on being a nurse. Nurs Sci. 2011;31(3):15-9.

21. Creswell JW, Plano Clark VL. Designing and conducting mixed methods research. 2011. Los Angeles, California.

22. Hall, R. Professionalization and bureaucratization. Am Sociol Rev. 1968;33(1):92-104.

23. Snizek, W. Hall's professionalism scale: An empirical reassessment. Am Sociol Rev. 1972;37:109-14.

24. Blezek, A. Professionalism of vocational agriculture instructors as perceived by vocational agriculture instructors and superintendents in Nebraska public secondary schools. 1987. Retrieved from http://digitalcommons.unl.edu/aglecfacpub/11

25. Breeden, L. et.al. The relationship among demographic variables, professionalism, and level of involvement in a state occupational therapy association. Occup Ther Health Care. 2000;12(2/3):53-72.

26. Shafer, W., Park, L., Lia, W. Professionalism, organizationalprofessional conflict and work outcomes: A study of certified management accountants. Accounting, Auditing, \& Accountability Journal. 2000;15(1):46-68.

27. Rosch TA, Reich, JN. The enculturation of new faculty in higher education: A comparative investigation of three academic departments. Res High Educ. 1996;37(1):115-31. 
28. McClellan D, Lordly D, Gingras, Professional socialization in dietetics: A review of the literature. Canadian Journal of Practice and Research. 2011;72(1):37-42.

29. Miller SE. A conceptual framework for the professional socialization of social workers. J Hum Behav Soc Environ. 2010;20(7):924-38.

30. Arthur, D. Measuring the professional self-concept of nurses: a critical review. J Adv Nurs. 1992;17:712-19.

31. McClure, K. Perceptions regarding the clinical laboratory profession and professionals. Clin Leadersh Manag Rev. 2008;22(3):E1-12.

32. Gray, M. Smith, LN. The professional socialization of diploma of higher education in nursing students (Project 2000): a longitudinal qualitative study. J Adv Nurs. 1999;29(3):639-47.

\section{Don't Miss the Spring 2017 Series by Outstanding Lab Experts!}

ASCLS members - register with special DISBOUNT BODE for a reduced site rate!

\section{Visit www.ascls.org/webinars for details}

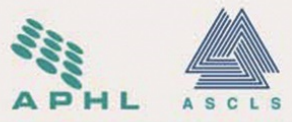

\section{APHL-ASCLS Webinar Series}

www.aphl.org/webinars 